\title{
Comparison of the Cockroft-Gault, simplified Modification of Diet in Renal Disease, and Chronic Kidney Disease Epidemiology Collaboration formulas in the determination of chronic kidney disease advancement
}

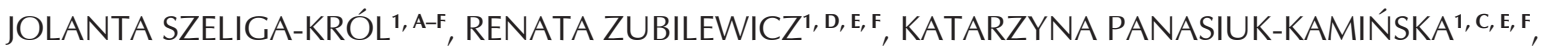 \\ WOJCIECH ZAŁUSKA ${ }^{2, A}$, c, D , MARCIN URBAŃCZUK¹, c, D, F, ANDRZEJ JAROSZYŃSKI 1, A, c-F
}

\author{
1 Department of Family Medicine, Medical University of Lublin
}

${ }^{2}$ Department of Nephrology, Medical University of Lublin

A - Study Design, B - Data Collection, C - Statistical Analysis, D - Data Interpretation, E - Manuscript Preparation, $\mathbf{F}$ - Literature Search, $\mathbf{G}$ - Funds Collection

\begin{abstract}
Summary Background. Chronic kidney disease (CKD) is at present a worldwide health problem. According to the National Kidney Foundation Kidney Disease Outcomes Quality Initiative (NKF KDOQI), chronic kidney disease has five stages of advancement based on the estimated glomerular filtration rate (eGFR). The formulas that are most frequently used in determining eGFR are the Cockroft-Gault (CG) formula, the simplified Modification of Diet in Renal Disease (MDRD) formula, and the Chronic Kidney Disease Epidemiology (CKD-EPI) Collaboration formula, which is considered the most accurate formula. Objectives. The aim of our study was to compare the CG, simplified MDRD and CKD-EPI formulas for determining eGFR and thus CKD advancement.

Material and methods. The study was conducted on a group of 202 patients with previously diagnosed CKD. To calculate the eGFR, the CG, simplified MDRD, and CKD-EPI formulas were used. Patients were assigned a disease stage (from 1 to 5) according to the NKF KDOQI guidelines.

Results. The calculated eGFR values varied depending on the formula, which resulted different assignations of patients to CKD stages. The largest difference regarded the qualification of the patients to the first and the fifth stage. A similar number of patients were classed as stage three by all formulas. Differences were also seen in how the formulas classified patients to the second and fourth stages.

Conclusions. GFR estimation remains a problematic clinical concern. The CKD stage assigned to patients varies depending on the formula used, a fact which may be particularly significant for general practitioners. Laboratories should apply the CKD-EPI formula for eGFR calculation, as it gives the least false results.

Key words: kidney, glomerular filtration rate, chronic kidney failure.
\end{abstract}

Fam Med Prim Care Rev 2016; 18(3): 348-351

\section{Background}

CKD is a worldwide health problem, and is now considered a disease of civilization [1]. Because of the rapidly increasing prevalence of CKD and the high growth in diseases that may cause CKD or accelerate its progression (such as diabetes, hypertension [2], autoimmune diseases, and overuse of nonsteroidal anti-inflammatory drugs), general practitioners (GPs) need to more and more often deal with CKD management and treatment.

CKD identification is based on the guidelines developed by the NKF KDOQI and accepted by the Kidney Disease Improving Global Outcomes (KDIGO) [3]. Thanks to a well-rounded diagnostic scheme, CKD can be diagnosed on the basis of two indicators: eGFR $\left(\mathrm{ml} / \mathrm{min} / 1.73 \mathrm{~m}^{2}\right)$ - which is commonly considered the best indicator of excretory renal function - and albuminuria (mg) [4].

CKD is a progressive disease; according to the NKF KDOQI, it can be divided into 5 stages, depending on eGFR values [3, 4]. The "gold standard" of the eGFR estimation is the determination of exogenous creatinine clearance and other markers [1], but for practical reasons these methods are not used, even in clinical practice. The "clinical stan- dard" for determining eGFR is to calculate it on the basis of endogenous creatinine clearance - a measurement that can be freely made under general practice conditions.

The Cockroft-Gault formula, introduced in 1976, was the first equation for eGFR estimation [5], and it gained popularity all over the world. Due to its limited accuracy, new formulas were sought. The next suggested equation was the MDRD formula and its simplified form [6], which is most frequently used formula for eGFR calculation in general practice. However, the search to discover a better equation for estimating GFR continued. In 2009 Levey et al. proposed a new formula, called the CKD-EPI Collaboration [7]. AIthough the MDRD and CKD-EPI formulas are based on the same variables, the newer equation is considered to be more accurate for estimating GFR [8].

In general practice, the most frequently used equations for GFR estimation are the simplified MDRD formula and the CG formula; the CKD-EPI formula is hardly used in daily routine. However, precise GFR estimation and accurate qualification of patients to a particular CKD stage has great clinical and prognostic significance, especially for general practitioners. The aim of our study was thus to compare eGFR values calculated with the use of these three formulas 
in different stages of CKD and to evaluate whether the results they give, and the difference between them, have statistical significance.

\section{Material and methods}

The study was conducted on a group of 202 subjects previously diagnosed with CKD and receiving treatment under primary care conditions and in a nephrology outpatient clinic. The group consisted of 100 women and 102 men. The age of the patients ranged from 18 to 91 years (mean age $57.6 \pm 17$ ). Only clinically stable adult patients were enrolled into our study. All patients signed a written informed consent form prior to participating in the study.

The causes of renal failure were glomerulonephritis (31.68\% of patients), diabetic nephropathy $(14.85 \%$ of patients), obstructive nephropathy (13.86\% of patients), hypertensive nephropathy $(11.38 \%$ of patients), tubulointerstitial nephritis (5.94\% of patients), renal polycystic kidney disease (4.45\% of patients), other secondary nephropathies (9.9\% of patients), and unknown reasons (7.92\% of patients).

Serum samples were collected from all patients according to the standard guidelines. Creatinine levels $(\mathrm{mg} / \mathrm{dl})$ were determined using an Advia 1800 Clinical Chemistry System, (Siemens). GFR was estimated using three equations:

- The Cockroft-Gault formula (CG): eGFR $=[(140-$ age $) \times$ body weight $] /[$ plasma creatinine $\times 72] \times(0.85$ if female $)$;

- The simplified Modification of Diet in Renal Disease equation (MDRD)

$\mathrm{eGFR}=186 \times$ [plasma creatinine $^{-1.154} \times[\text { age }]^{-0.203} \times$ [0.742 if female $] \times[1.21$ if black $]$;
- $\quad$ and the Chronic Kidney Disease Epidemiology Collaboration (CKD-EPI)

eGFR $=$ for women with a plasma creatinine $\leq 0.7$ : [plasma creatinine/0.7 $]^{-0.329} \times[0.993]^{\text {age }}[\times 166$ if black; $\times 144$ if white or other]; for women with a plasma creatinine $>$ 0.7: [plasma creatinine/0.7 $]^{-1.209} \times[0.993]^{\text {age }}[\times 166$ if black; $\times 144$ if white or other]; for men with a plasma creatinine $\leq$ 0.9: [plasma creatinine/0.9 $]^{-0.411} \times[0.993]^{\text {age }}[\times 163$ if black; $\times 141$ if white or other];for men with a plasma creatinine $>$ 0.9 : [plasma creatinine/0.9 $]^{-1.209} \times[0.993]^{\text {age }}[\times 166$ if black; $\times 141$ if white or other].

Estimated glomerular filtration rates are expressed in $\mathrm{ml} /$ $/ \mathrm{min} / 1.73 \mathrm{~m}^{2}$

On the basis of the three calculated eGFR values, each patient was classified to particular CKD stages.

The results were statistically analyzed using Statistica 8.0. The arithmetic mean and standard deviation for the eGFR values obtained, in particular the CKD stages, were calculated. Student's $t$-test and the level of significance were also applied to compare the differences between the eGFR values and the CKD stages resulting from each formula (values of $p<0.05$ were considered statistically significant). Furthermore, the Bland-Altman plot was used to illustrate the agreement between the formulas.

\section{Results}

The estimated GFR values varied depending on the formula used. The results of the calculations are illustrated in Tables 1, 2, 3, and 4.

The application of the three formulas resulted in the assignment of different numbers of patients to each CKD stage.

\begin{tabular}{|c|c|c|c|c|c|c|}
\hline \multirow[t]{2}{*}{ CKD stage } & \multicolumn{2}{|c|}{ The Cockroft-Gault formula } & \multicolumn{2}{|c|}{ The Simplified MDRD formula } & \multicolumn{2}{|c|}{ The CKD-EPI Collaboration } \\
\hline & $\begin{array}{l}\text { Number of } \\
\text { patients }\end{array}$ & $\begin{array}{l}\text { Percentage } \\
\text { of patients }\end{array}$ & $\begin{array}{l}\text { Number of } \\
\text { patients }\end{array}$ & $\begin{array}{l}\text { Percentage } \\
\text { of patients }\end{array}$ & $\begin{array}{l}\text { Number of } \\
\text { patients }\end{array}$ & $\begin{array}{l}\text { Percentage } \\
\text { of patients }\end{array}$ \\
\hline 1 & 42 & $20.8 \%$ & 26 & $12.9 \%$ & 30 & $14.8 \%$ \\
\hline 2 & 34 & $16.8 \%$ & 35 & $17.3 \%$ & 29 & $14.3 \%$ \\
\hline 3 & 75 & $37.1 \%$ & 75 & $37.1 \%$ & 71 & $35.1 \%$ \\
\hline 4 & 36 & $17.8 \%$ & 47 & $23.3 \%$ & 46 & $22.7 \%$ \\
\hline 5 & 15 & $7.4 \%$ & 19 & $9.4 \%$ & 26 & $12.8 \%$ \\
\hline
\end{tabular}

\begin{tabular}{|c|c|c|c|c|c|c|}
\hline \multirow[t]{2}{*}{ CKD stage } & \multicolumn{2}{|c|}{$\begin{array}{l}\text { eGFR (mean value) }\left(\mathrm{ml} / \mathrm{min} / 1.73 \mathrm{~m}^{2}\right) \\
\text { according to the simplified MDRD formula }\end{array}$} & \multicolumn{2}{|c|}{$\begin{array}{l}\text { eGFR (mean value) }\left(\mathrm{ml} / \mathrm{min} / 1.73 \mathrm{~m}^{2}\right) \\
\text { according to the } \mathrm{CG} \text { formula }\end{array}$} & \multicolumn{2}{|c|}{ Student's t-test results } \\
\hline & Mean & SD & Mean & SD & $t$ & $p$ \\
\hline 1 & 110.8 & 20.6 & 130.9 & 38.8 & -3.4 & 0.0022 \\
\hline 2 & 75.4 & 8.4 & 91.3 & 20.6 & -5.3 & $<0.0001$ \\
\hline 3 & 42.8 & 9.9 & 49.9 & 12.5 & -5.0 & $<0.0001$ \\
\hline 4 & 23.3 & 5.0 & 28.4 & 8.4 & -4.7 & $<0.0001$ \\
\hline 5 & 11.0 & 3.1 & 14.0 & 4.8 & -6.0 & $<0.0001$ \\
\hline
\end{tabular}

\begin{tabular}{|c|c|c|c|c|c|c|}
\hline \multirow[t]{2}{*}{ CKD stage } & \multicolumn{2}{|c|}{$\begin{array}{l}\text { eGFR (mean value) }\left(\mathrm{ml} / \mathrm{min} / 1.73 \mathrm{~m}^{2}\right) \\
\text { according to the } \mathrm{CG} \text { formula }\end{array}$} & \multicolumn{2}{|c|}{$\begin{array}{l}\text { eGFR (mean value) }\left(\mathrm{ml} / \mathrm{min} / 1.73 \mathrm{~m}^{2}\right) \\
\text { according to the CKD-EPI formula }\end{array}$} & \multicolumn{2}{|c|}{ Student's t-test results } \\
\hline & Mean & SD & Mean & SD & $t$ & $p$ \\
\hline 1 & 130.9 & 38.8 & 104.8 & 10.6 & -13.4 & $<0.0001$ \\
\hline 2 & 91.3 & 20.6 & 77.8 & 9.1 & -7.1 & $<0.0001$ \\
\hline 3 & 49.9 & 12.5 & 47.4 & 7.8 & -1.2 & 0.22826 \\
\hline 4 & 28.4 & 8.4 & 23.2 & 3.9 & -8.8 & $<0.0001$ \\
\hline 5 & 14.0 & 4.8 & 11.1 & 3.1 & -6.3 & $<0.0001$ \\
\hline
\end{tabular}




\begin{tabular}{|c|c|c|c|c|c|c|}
\hline \multirow[t]{2}{*}{ CKD stage } & \multicolumn{2}{|c|}{$\begin{array}{l}\text { eGFR (mean value) }\left(\mathrm{ml} / \mathrm{min} / 1.73 \mathrm{~m}^{2}\right) \\
\text { according to the simplified MDRD formula }\end{array}$} & \multicolumn{2}{|c|}{$\begin{array}{l}\text { eGFR (mean value) }\left(\mathrm{ml} / \mathrm{min} / 1.73 \mathrm{~m}^{2}\right) \\
\text { according to the CKD-EPI formula }\end{array}$} & \multicolumn{2}{|c|}{$\begin{array}{l}\text { Student's } t \text {-test } \\
\text { results }\end{array}$} \\
\hline & Mean & SD & Mean & SD & $t$ & $p$ \\
\hline 1 & 110.8 & 20.6 & 104.8 & 10.6 & -3.0 & 0.0045 \\
\hline 2 & 75.4 & 8.4 & 77.8 & 9.1 & 1.3 & 0.2031 \\
\hline 3 & 42.8 & 9.9 & 47.4 & 7.8 & 2.2 & 0.0264 \\
\hline 4 & 23.3 & 5.0 & 23.2 & 3.9 & -0.1 & 0.9158 \\
\hline 5 & 11.0 & 3.1 & 11.1 & 3.1 & 0.2 & 0.7669 \\
\hline
\end{tabular}

The greatest difference was seen for stage five and the smallest difference concerned the stage three (Tab. 1). The differences between the mean eGFR values in each CKD stage were statistically significant $(p<0.05)$ when comparing the CG formula to the MDRD and CKD-EPI formulas (Tab. 2 and 3). The differences between the results obtained from the simplified MDRD and CKD-EPI formulas were not statistically significant (Tab. 4).

The results are also presented as Bland-Altman plots in Figures 1, 2, and 3. The $y$-axis in each graph represents the difference between the eGFR values, while the $x$-axis represents the mean of the eGFR values.

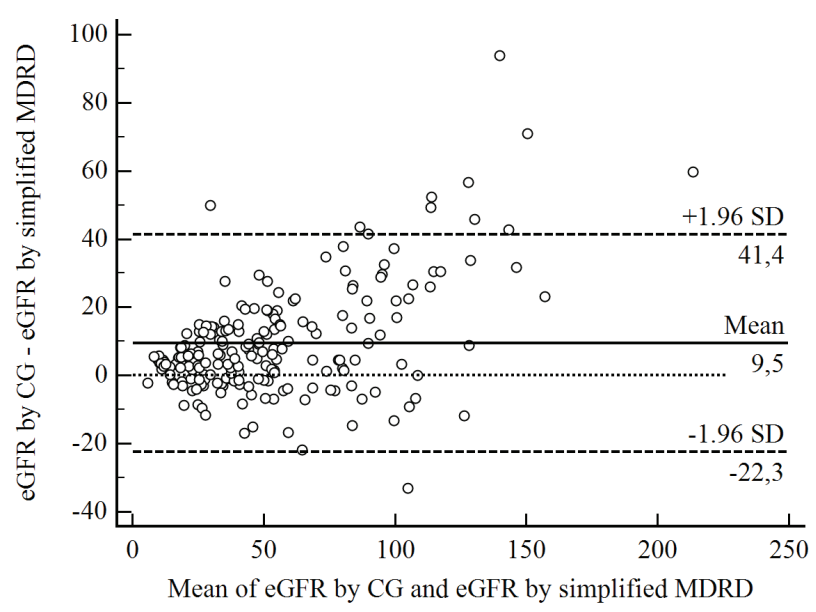

Figure 1. Bland-Altman plot illustrating the agreement between the CG and the simplified MDRD formulas in CKD patients

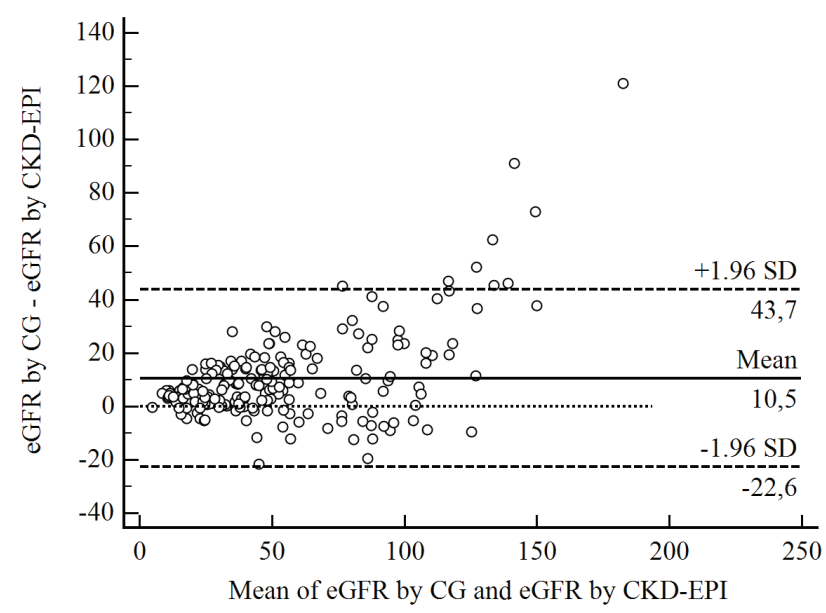

Figure 2. Bland-Altman plot illustrating the agreement between the CG and the CKD-EPI formulas in CKD patients

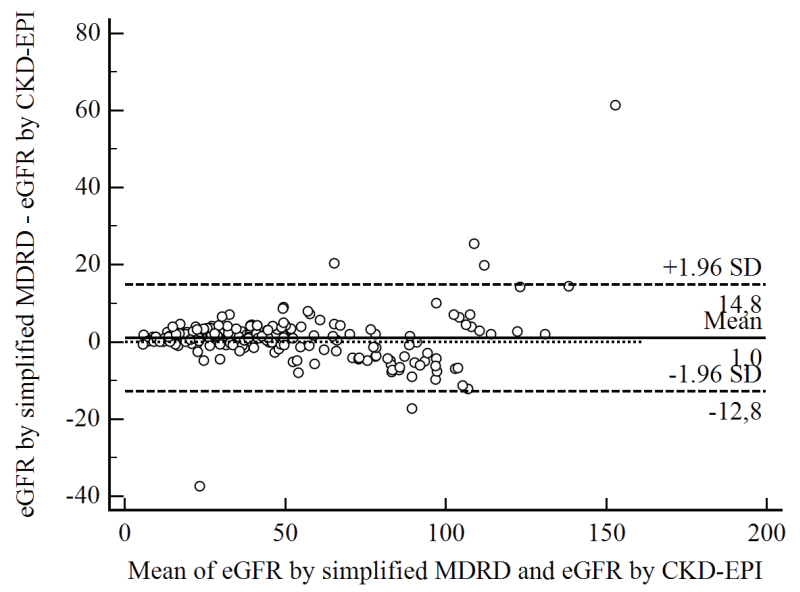

Figure 3. Bland-Altman plot illustrating the agreement between the simplified MDRD and the CKD-EPI formulas in CKD patients

\section{Discussion}

GFR estimation remains a very important clinical concern, not only for nephrologists, but also for GPs. Decisions about whether patients should be referred to a nephrologist are made in part on the basis of the eGFR value. Moreover, the dose of many medications prescribed by GPs depends on the eGFR value. Since, in general practice, eGFR calculations are performed using all three equations, we wondered how the results of the formulas compare.

The CG formula remains very popular because of its simple structure. It is most often used when there is no automatic laboratory to perform the eGFR calculation. According to our results, the differences in mean eGFR values for each CKD stage obtained with the use of the CG formula and the other equations were in most cases statistically significant ( $p$ $<0.05$ ). With the CG formula, most patients were qualified to the first stage and fewest to the fourth and fifth stages, as compared to other formulas; this may have negative clinical and practical ramifications.

The simplified MDRD formula is most frequently used in general practice and is nowadays used by most laboratories. However, in the light of recent studies, the KDIGO suggests that the CKD-EPI formula is the best for eGFR calculation [8]. According to our study, the differences in the values obtained using the CKD-EPI and simplified MDRD formulas were not statistically significant, as was the case with the CG formula. Hence, we can assume that when it is impossible to use the CKD-EPI formula (such as under GP conditions), the simplified MDRD equation may be acceptable. However, taking into consideration the fact that both formulas are based on the same variables, laboratories should be required to automatically calculate the eGFR according to the KDIGO guidelines. 


\section{Conclusions}

Estimating GFR remains an important clinical concern, especially in everyday GP practice. Taking into consideration the fact that there are only small differences between results obtained with the simplified MDRD formula and the CKD-EPI formula, and the fact that most laboratories calculate eGFR using the simplified MDRD formula, we suggest that, where necessary for practical reasons, GPs should for the time being use the simplified MDRD formula. In questionable situations, it may make sense for them to additionally apply the CKD-EPI formula. It seems reasonable that both nephrologists and GPs to expect that laboratories use the CKD-EPI formula in eGFR calculations where ever possible.

Source of funding: This work was funded by the authors' resources.

Conflict of interest: The authors declare no conflict of interests.

\section{References}

1. Nowicki M. Metody wykrywania i oceny postępu przewlekłej choroby nerek. Chor Serca Naczyń 2007; 4(3): $137-141$.

2. Mastalerz-Migas A, Muszyńska A, Doskocz K, et al. Wpływ otyłości i nadwagi na funkcję nerek w populacji pacjentów praktyki lekarza rodzinnego. Fam Med Prim Care Rev 2014; 16(2): 133-135.

3. National Kidney Foundation. K/DOQI clinical practice guidelines for chronic kidney disease: evaluation, classification and stratification. Am J Kidney Dis 2002; 39(Suppl. 1): 1-26.

4. Mastalerz-Migas A, Steciwko A. Częstość występowania zaburzeń funkcji nerek w populacji pacjentów praktyki lekarza rodzinnego - doniesienie wstępne. Fam Med Prim Care Rev 2012; 14(3): 399-402.

5. Cockroft DW, Gault MH. Prediction of creatinine clearance from serum creatinine. Nephron 1976; 16(1): 31-41.

6. Levey AS, Bosch JP, Jacquot C, et al. A more accurate method to estimate glomerular filtration rate from serum creatinine: a new prediction equation. Modification of Diet in Renal disease Study Group. Ann Intern Med 1999; 130(6): 461-470.

7. Levey AS, Stevens LA, Schmid CH, et al. A new equation to estimate glomerular filtration rate. Ann Intern Med 2009; 150(9): 604-612.

8. Improving Global Outcomes (KDIGO) CKD Work Group. KDIGO 2012 Clinical Practice Guideline for the Evaluation and Management of Chronic Kidney Disease. Kidney Int Suppl 2013; 3(3): 1-150.

Address for correspondence:

Jolanta Szeliga-Król, MD, PhD

Katedra i Zakład Medycyny Rodzinnej UM

ul. Langiewicza 6A

20-032 Lublin

Polska

Tel.: +48 81 524-78-56

E-mail: jolaszeliga@wp.pl

Received: 29.03.2016

Revised: 22.04.2016

Accepted: 22.04.2016 